BIORHEOLOGY $19 ; 105-108,1982$

0006-355X/82/010105-04\$03.00/0 Printed in the USA.

Copyright (c) 1982 Pergamon Press Ltd. All rights reserved.

\title{
POISEUILLE GOLD MEDAL AWARD CEREMONY INTRODUCTORY REMARKS
}

\author{
Harold Wayland \\ Professor of Engineering Science Emeritus \\ California Institute of Technology \\ Pasadena, California 91125, USA
}

Mr. Chairman, Members of our Society and of this Congress, Ladies and Gentlemen,

It is a great honor for me to have the privilege of introducing our Poiseuille Awardee, Professor Alexander Silberberg, Head of the Department of Polymer Research and Director of the Aharon Katzir-Katchalsky Center at the Weizmann Institute of Science in Rehovot, Israel. This introductory talk should, properly, have been made by Professor Maurice Joly, the 1978 Poiseuille Award winner, who, unfortunately, is unable to be with us.

Professor Silberberg was born in Vienna, Austria, in 1925, moving to Johannesburg, South Africa, when he was twelve. In 1944 he was graduated from the University of Witwatersrand, Johannesburg with a B.Sc. (Eng.) degree in Chemical Engineering. After a period of war service, he entered the University of Basel, Switzerland in 1948 to study with Professor Werner Kuhn, receiving his $\mathrm{Ph} . \mathrm{D}$. degree in 1952, "Summa cum Laude", for a thesis in Physical Chemistry entitled: "Interfacial Tension and Phase Separation in Two Polymer-Solvent Systems". He stayed another year with Professor Kuhn, and then joined the Weizmann Institute of Science in 1953. This has been his base of operations ever since, being appointed Professor in 1970. During various leaves from the Weizmann Institute, he has held visiting appointments at major institutions in the U.S., Denmark and Great Britain. He has published widely, and has been active in a variety of professional societies, including our own International Society of Biorheology, of which he was President in 1972-1978. He has made substantial contributions on the editorial boards of several journals, and is an Editor-in-Chief of our own journal, "Biorheology".

The design of the Poiseuille Medal was made by the famous Icelandic artist Nina Tryggvadottir, better known to many of us as Mrs. A.L. Copley. It was first presented to Robin Fåhraeus at the First International Congress of Hemorheology, which was held in Rejkjavik, Iceland, in 1966. The association of the names of Poiseuille and Fahraeus was doubly appropriate, since Poiseuille un- 
dertook his pioneering work on the flow of liquids through small tubes in the hope of better understanding the flow of blood in blood vessels, while Professor Făhraeus made important pioneering contributions to the role of erythrocytes in modifying the nature of blood flow in microvessels. This first award was presented in the name of the International Society of Hemorheology.

The idea for an International Society of Biorheology was strongly urged by Professor Hellmut Hartert at an informal dinner meeting which I had organized in conjunction with the Fourth International Congress of Rheology held at Brown University in Providence, Rhode Island, in 1963. In connection with this Congress, Professor A.L. Copley had organized an excellent Symposium on Biorheology. Since many of the papers were on blood flow, it seemed desirable to bring together those interested in this topic for informal exchange of ideas. Our current President, Dr. Eiichi Fukada, and our current Poiseuille Awardee were among those attending this dinner. Although there was considerable enthusiasm expressed for the immediate organization of such a society, it was finally agreed that it was premature to undertake to do so at that time. Professor Copley had been interested in such an organization for some considerable time, and, in conjunction with the co-Editorin-Chief of the journal "Biorheology", Dr. George W. Scott Blair, he organized the First International Conference of Hemorheology which was held in Iceland in 1966. At this time the International Society of Hemorheology was formally organized. In 1969 the Second International Congress of Hemorheology was held at Heidelberg, F. R. Germany, when the Poiseuille Award was given to Dr. Scott B1air.

By this time there was considerable interest in obtaining some sort of affiliation with an established international body. With important assistance from Professor Aharon Katzir-Katchalsky of the Weizmann Institute, an affiliation with the International Union of Pure and Applied Biophysics was finally consumated, but only on the condition that the Society broadens its charter to include all of biorheology.

The first Congress under the new name and sponsorship took place in Lyon, France in 1972, at which time Professor Copley received the Poiseuille Award. Professor Syoten Oka was the Poiseuille Awardee at the Congress in Jerusalem, Israel in 1975, and the fifth awardee was $\mathrm{Dr}$. Maurice Joly, who received his award at La Jo11a, California, in 1978. So, even though many of us consider that our Society was "conceived" in 1963 and, after a long period of gestation was "born" in 1966, the Poiseuille Medal is about to be awarded for the sixth time, this meeting is 1isted as only the Fourth International Congress of Biorheology. It would seem to me to be appropriate to honor our ancestry and call this the Sixth International Congress. After all, a woman's name may be changed by marriage, but not her age!

This year's awardee represents to me the epitome of the multidisciplinary character of biorheology. My first memory of Alex Silberberg is from a meeting of the European Society for Microcirculation which was held in Pavia, Italy, in 1962. At that time he reported on the tubular pinch effect, in which rigid particles, which are carried in Poiseuille flow in small concentration in a 
circular tube, tend to concentrate in an annular ring some distance from the wall. (word he had done in collaboration with an Italian Colleagre Dr. Segrè). This was essentially a complex problem in classical fluid mechanics. (But isn't classical fluid mechanics the starting point for the rheology of fluids?)

We next met at the "conception" dinner in Providence, al though his paper at the congress was not on biorheology. Our next contact was at the time of the meeting of the European Society for Microcirculation which was held in Jerusalem in 1964. After the meeting Wallace Frasher and I, along with our wives, had lunch with the Silberbergs in their apartment in Rehovot. We three men had a long discussion as to the future of someone with Alex's background in chemical engineering and polymer science in biological studies (and, in particular, in studies of blood rheology). Alex was questioning the validity of his continuing in this field, and Frasher and I were arguing that we felt it extremely important that he not abandon i.t. Whether or not that discussion had any bearing on his ultimate decision, all of us here can be pleased that he has not only continued with his interest in hemorheology, but has greatly broadened his scope to include many other aspects of biorheology.

Rather than merely catalogue Professor Silberberg's many contributions to the field of biorheology, I would like to emphasize what I feel to be his most important conceptual contribution.

Professor Silberberg has brought to biorheology a broad background in physical and polymer chemistry which he has employed in trying to understand the molecular basis for the rheological behavior of various biological systems. For example, he has not been content with a mere mathematical description of how cervical mucus flows under a particular pattern of external forces. He wants to know the relationship of the molecular structure of the mucus to i.ts flow properties. In his studies of blood-to-lymph transport of various molecular species, he has given careful consideration to both the physical and chemical makeup of the interstitial space through which these materials move. In 1968-69, Professor Silberberg spent a year as a Visiting Fellow of the American Heart Association at the University of Washington in Seattle, working in close collaboration with one of the outstanding microcirculatory experimentalists in the world, Professor Curt Wiederhielm. (At that time many thought that hyaluronic acid was the major factor determining macromolecular exclusion in soft connective tissue.) As anyone who has followed this complex problem in detail. will know, he soon showed that the problem was much more complicated than had been anticipated. He has contjnued his studies on polymeric entanglement and interaction in connective tissue and its relationship to interstitial transport. An excellent summary has appeared in a joint paper with Professor Benjamin Zweifach, much of which was written while Professor Silberberg was a Fairchild Distinguished Scholar at my own institution, The California Institute of Technology, in 1977.

Professor Silberberg's contributions to biorheology have shown the great importance of a multidiscip1inary and multi-pronged attack on the complicated problems of deformation and flow in bio- 
logical systems: the need for accurate determination of the phenomena involved by use of carefully designed (although often simple) experiments; clear analytical formulation of the results; and ultimately an attack on understanding these results by exploring the molecular basis of the phenomena. There are a few of us in the field who can bring such a rich diversity of background to bear on these important problems. We are fortunate to have the privilege of honoring such a scientist by presenting him with the highest award given by our Society.

And now I would like to turn the meeting over to Professor Syoten Oka, the Poiseuille Award winner in 1975, to make the formal presentation. 